\title{
Conditional expression of anti-apoptotic protein p35 by Cre-mediated DNA recombination in cardiomyocytes from loxP-p35-transgenic mice
}

\author{
T Araki ${ }^{1,3}$, M Shibata $^{1,4}$, R Takano ${ }^{1}$, S Hisahara ${ }^{1}$, \\ S-i Imamura ${ }^{5}$, Y Fukuuchi ${ }^{4}$, T Saruta ${ }^{3}$, H Okano ${ }^{1,2}$ \\ and M Miura ${ }^{*, 1,2}$ \\ ${ }^{1}$ Division of Neuroanatomy, Osaka University Graduate School of Medicine, 2-2 \\ Yamadaoka, Suita, Osaka 565-0871, Japan \\ 2 CREST of Japan Science and Technology Corporation (JST), Osaka University \\ Graduate School of Medicine, 2-2 Yamadaoka, Suita, Osaka 565-0871, Japan \\ ${ }^{3}$ Department of Nephrology, Internal Medicine, Keio University School of \\ Medicine, 35 Shinanomachi, Shinjyuku-ku, Tokyo 160-8582, Japan \\ 4 Department of Neurology, Keio University School of Medicine, 35 \\ Shinanomachi, Shinjyuku-ku, Tokyo 160-8582, Japan \\ ${ }^{5}$ Research Division, The Heart Institute of Japan, Tokyo Women's Medical \\ College, 8-1 Kawada-cho, Shinjuku-ku, Tokyo 162-0054 \\ * Corresponding author: M Miura, Division of Neuroanatomy (D12), Osaka \\ University Graduate School of Medicine, 2-2 Yamadaoka, Suita, Osaka 565- \\ 0871, Japan. Tel: +81-6-6879-3581; Fax: +81-6-6879-3589; \\ E-mail:mmiura@nana.med.osaka-u.ac.jp
}

Received 12.8.99; revised 20.12.99; accepted 3.2.00

Edited by SJ Martin

\begin{abstract}
p35, a viral inhibitor of caspase, prevents cell death induced by various stimuli. We established an experimental system to study the involvement of caspases in cell death, using primary cultured cells from p35 transgenic mice in which the p35 open reading frame (ORF) had been disrupted by the insertion of a DNA segment flanked by loxP sites, the Cre recognition sites. In this system, p35 expression can be initiated by Cre recombinase. Cardiomyocytes, which are highly sensitive to hypoxic stress, were infected with an adenovirus carrying the cre gene (AxCANCre). Expression of p35 by infection with AxCANCre resulted in inhibition of caspase-3 activation and resistance to hypoxia-induced cell death. Hypoxia-induced cytochrome $\mathrm{c}$ release was also attenuated in p35-expressing cardiomyocytes. Our transgenic mice can be used as an experimental model for studying the involvement of caspases in various degenerative diseases as well as programmed cell death both in vitro and in vivo. Cell Death and Differentiation (2000) 7, 485-492.
\end{abstract}

Keywords: p35; caspases; cardiomyocytes; hypoxia; cre/loxP

Abbreviations: PBS, phosphate-buffered saline; FBS, fetal bovine serum; RT - PCR, reverse transcription PCR; DMEM, Dulbecco's modified Eagle's medium

\section{Introduction}

Caspases are common mediators of cell death induced by diverse stimuli. Pharmaceutical caspase inhibitors such as Z-
VAD-fmk and Z-DEVD-fmk, are widely used to study the involvement of caspases in cell death. However, because of their non-specific effects on proteases other than caspases, and because they have different cell permeabilities and are toxic for certain types of cells, there are substantial limitations to their applications. In contrast to pharmaceutical inhibitors, viral inhibitors of caspases are highly specific for caspases, and are considered more suitable for studying the role of caspases in physiological cell death. A viral inhibitor for cytokine response modifier $A(\mathrm{crmA})$, has been shown to block the activation of caspase- 1 and $-8^{1,2}$ and to prevent the cell death induced by Fas, TNF, and growth factor deprivation. ${ }^{3-6}$ Another viral inhibitor of caspases, the baculovirus gene product $\mathrm{p} 35$, is a more potent suppressor of programmed cell death in Caenorhabditis elegans ( $C$. elegans) and Drosophila. ${ }^{7-9}$ Expression of $p 35$ in insect and mammalian cells prevents cell death induced by different signals. ${ }^{10-17}$ In vitro data indicate that $\mathrm{p} 35$ effectively inhibits mammalian caspase- $1,-2,-3,-4,-6,-7,-8,-10$, and $C$. elegans Ced-3. ${ }^{18-22}$ Inhibition of all effector phase caspases (caspase- $3,-6,-7$ ) by p35 strongly suggests that p35 can be used as a general inhibitor of cell death in mammals.

A transgenic mouse expressing $\mathrm{crm} A$ in the thymus has been produced. ${ }^{1,2}$ While crmA expression inhibits in vitro Fas-induced apoptosis, it does not affect the negative selection driven by the minor lymphocyte stimulating antigen or the endogenous $\mathrm{H}-\mathrm{Y}$ antigen. In contrast, transgenic mice expressing $\mathrm{p} 35$, a broad-range inhibitor of the caspase family, in thymocytes did show inhibition of MHC classll-restricted negative selection induced by staphylococcal enterotoxin B (SEB) superantigen. ${ }^{23}$ This result raises the possibility that transgenic mice carrying p35 can be used to study the mechanisms underlying cell death mediated by caspases.

There are some difficulties in producing p35 transgenic mice. Prevention of caspase activity in the early embryo could result in an embryonic lethal phenotype because the knockout of certain caspase family members (caspase- $3,-8$ and -9) causes embryonic lethality. ${ }^{24-28}$ We have generated mice carrying a p35 gene that can be expressed ubiquitously but that is not expressed under normal conditions because its open reading frame (ORF) has been disrupted by the insertion of a DNA segment flanked by loxP sites, the Cre recognition sites. ${ }^{29}$ Expression of $\mathrm{Cre}$, which mediates recombination of two loxP sites into a single site, with concomitant removal of the DNA segment they flank, restores the p35 ORF, thereby allowing production of p35 in the cell population of interest.

Here, we evaluated the p35 expression system in cardiomyocytes undergoing cell death under hypoxic conditions. Several studies have reported the involvement of caspases in hypoxia-induced cardiomyocyte injury using the pan-caspase inhibitor Z-VAD-fmk. ${ }^{30}$ However, Z-VAD-fmk has been reported to also inhibit calpain, ${ }^{31}$ it is difficult to 
conclude that caspases were specifically involved. To address this issue more directly, we examined the anti-cell death function of p35 in cardiomyocytes derived from p35 transgenic mice. Cardiomyocytes were infected with an adenovirus carrying the cre gene (AxCANCre), ${ }^{32}$ and their sensitivity to hypoxia-induced cell death was tested. Expression of p35 after infection with AxCANCre resulted in a significant resistance to hypoxia-induced cell death. Consistent with this observation, activation of caspase-3 and release of cytochrome $\mathrm{c}$ were attenuated in p35-expressing cardiomyocytes under hypoxic conditions. Our results indicate that caspase activation plays a crucial role in hypoxia-induced cardiomyocyte injury. Our transgenic mice can be used as an experimental model for studying the involvement of caspases in various degenerative diseases as well as programmed cell death both in vitro and in vivo.

\section{Results}

\section{Experimental design of Cre-loxP ON/OFF system-mediated $\mathrm{p} 35$ expression}

In our p35 transgenic mice, a p35 transgene that can not produce p35 protein until it has been 'activated' by Cre- mediated DNA recombination was constructed by inserting the neo gene as a stuffer flanked by loxP sites between the CAG promoter, and the p35 coding sequence (Figure 1A). The CAG promoter consists of the cytomegalovirus IE enhancer and the chicken $\beta$-actin promoter, and enables efficient production of the gene of interest in most mouse tissues. ${ }^{33}$ Cre-mediated recombination of the two loxP sites yields a single loxP site with the concomitant deletion of the neo gene, placing the $p 35$ gene under the control of the CAG promoter (Figure 1A).

We examined the expression of the neo gene by RTPCR to determine whether or not the CAG promoter was working ubiquitously in the transgenic mice. neo expression could be detected by RT-PCR as an 800-bp fragment using the neo- 2 and neo-3 primers. Expression of the neo gene was detected in most of the adult tissues tested, except for the liver and spleen (Figure 1B). It is unclear why neo was not expressed in the liver and spleen. Transgenic mice carrying a CAG-loxP- $\beta$ Geo-loxPhuman placental alkaline phosphatase gene has been made and examined the expression of transgene. ${ }^{34}$ Although the transgene is widely expressed, to date, transgenic lines with proven ubiquitous expression have not been made. ${ }^{34}$ Since the activity of most promoters is
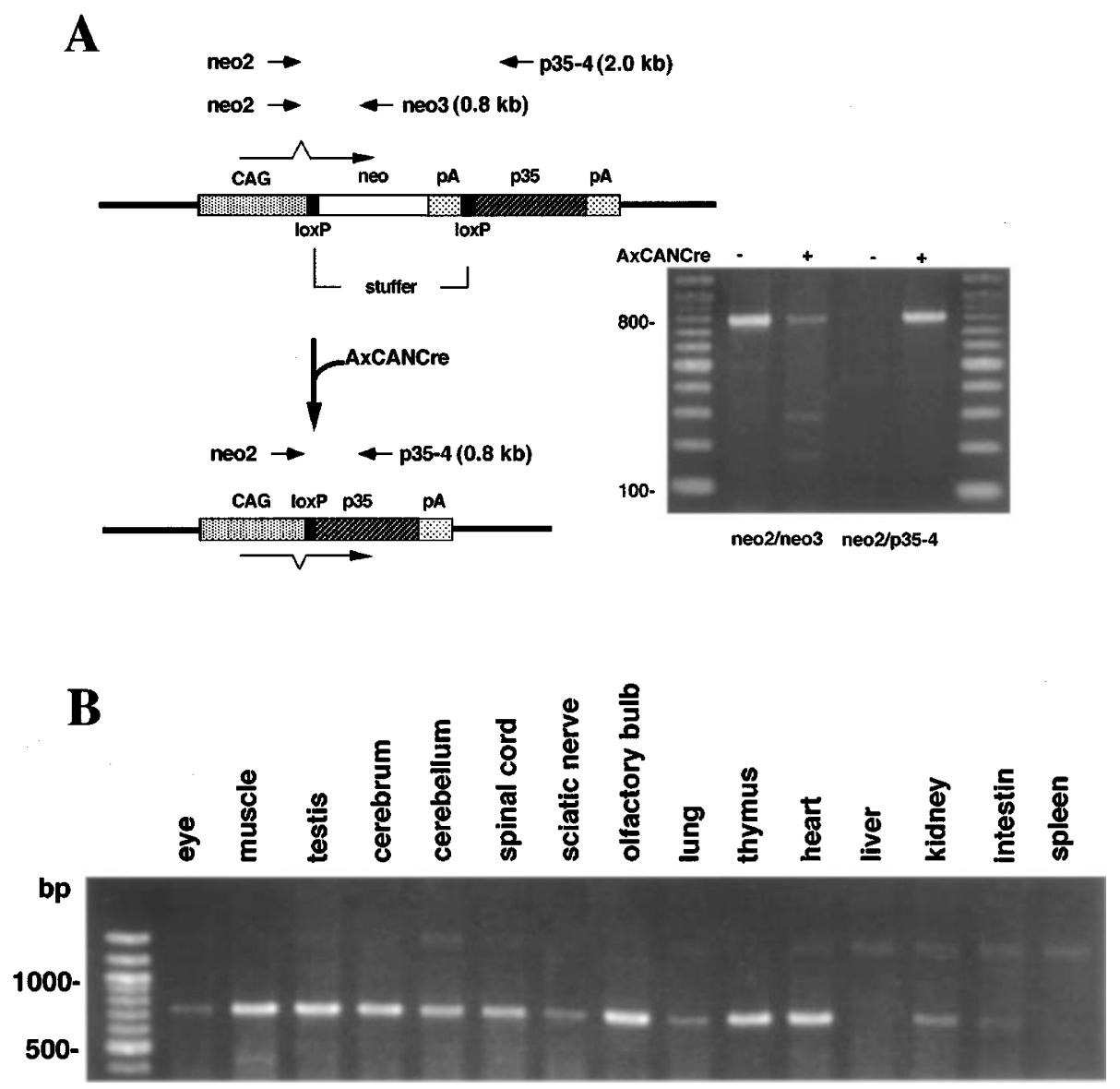

Figure 1 (A) Schematic representation of the structure of the p35 transgene, and Cre-mediated removal of the stuffer sequence. Right panel shows the expression of $p 35$ revealed by RT - PCR using neo 2 and p35-4 primers. Cardiomyocytes were infected with adenovirus $\left(2 \times 10^{5} \mathrm{pfu} / \mathrm{ml}\right)$ for $24 \mathrm{~h}$, then total RNA was isolated. Expression of $p 35$ was initiated by infection of cardiomyocytes with AxCANCre. (B) Expression of the neo gene was detected by RT - PCR using the neo2 and neo3 primers in various tissues 
integration-site dependent, the integration site of our p35 transgenic mice could affect the activity of the CAG promoter in liver and spleen.

\section{Cre-mediated expression of p35 prevents cardiomyocyte cell death induced by hypoxia}

To evaluate the anti-cell death function of p35 in response to hypoxia, cardiomyocytes were infected with a replication-

\section{A}

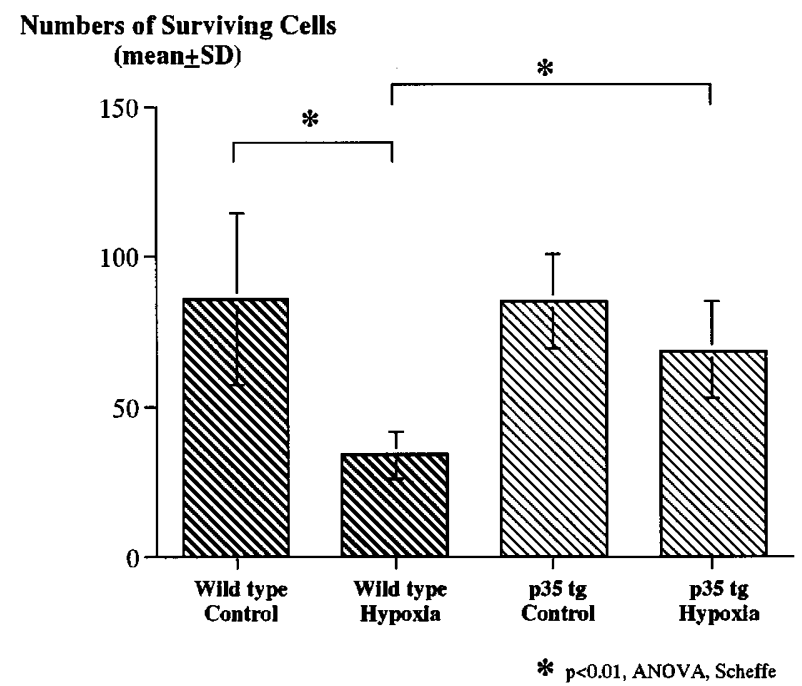

B

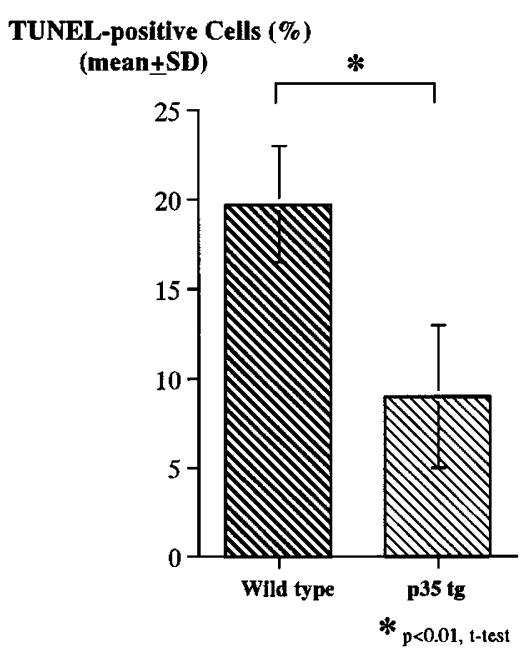

Figure 2 (A) Changes in numbers of cardiomyocytes in response to hypoxia. Cardiomyocytes from wild-type and p35-transgenic (p35 tg) mice were infected with adenovirus $\left(2 \times 10^{5} \mathrm{pfu} / \mathrm{ml}\right)$ for $24 \mathrm{~h}$, then placed under hypoxic conditions for $48 \mathrm{~h}$. The cells were counted and the data were expressed as means \pm S.D. The results were obtained from 20 independent visual fields. The asterisks in the figure represent $P$-values below 0.01 . (B) Hypoxia-induced DNA fragmentation. Cardiomyocytes from wild-type and p35-transgenic (p35tg) mice were infected with adenovirus $\left(2 \times 10^{5} \mathrm{pfu} / \mathrm{ml}\right)$ for $24 \mathrm{~h}$, then placed under hypoxic conditions for $48 \mathrm{~h}$. DNA fragmentation was detected by TUNEL staining. The data were expressed as means \pm S.D. The results were obtained from six independent visual fields. The asterisks in the figure represent $P$ values below 0.01

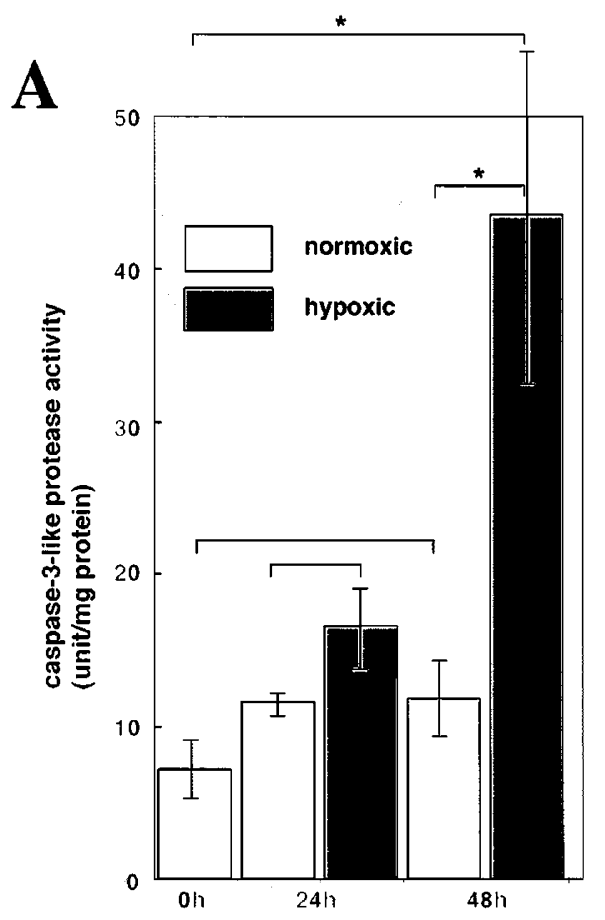

B

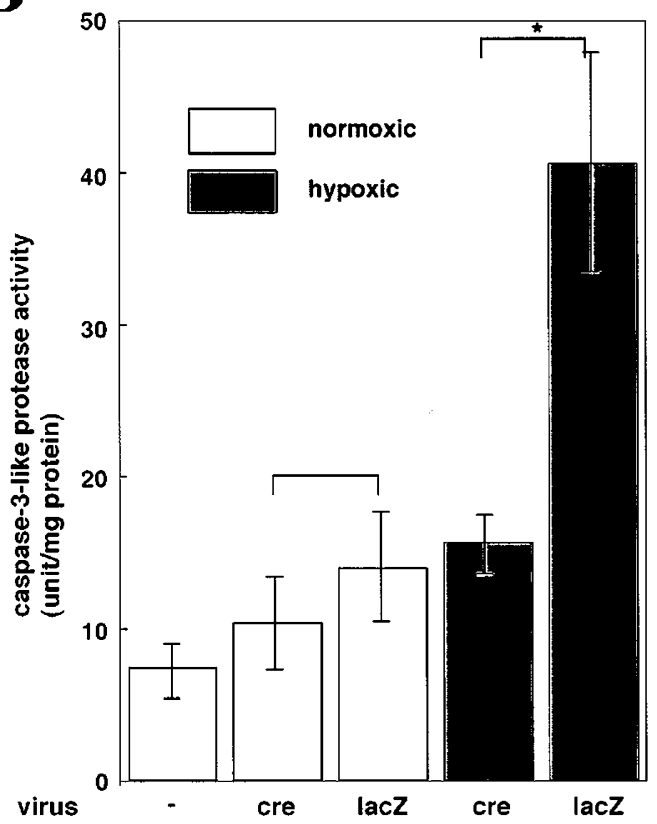

Figure 3 (A) Caspase-3-like protease activity of cardiomyocytes in hypoxia. At $48 \mathrm{~h}$ in culture, caspase-3-like activity was $43.5+21.8(n=3)$ in hypoxic conditions and $11.8+5.0(n=3)$ in normoxic conditions. Statistical analysis was performed using Student's $t$-test. The asterisks in the figure represent $P$ values below 0.05 . (B) Inhibition of caspase-3-like protease activity in cardiomyocytes expressing p35. Cardiomyocytes from p35 transgenic mice were infected with adenovirus $\left(2 \times 10^{5} \mathrm{pfu} / \mathrm{ml}\right)$ for $24 \mathrm{~h}$, then placed under hypoxic conditions for $48 \mathrm{~h}$. Cell lysates were extracted and caspase activity was measured. Caspase-3-like activity was $40.5 \pm 6.6(n=3)$ in AxCALacZinfected cardiomyocytes and $15.7 \pm 3.6 \quad(n=3)$ in AxCANCre-infected cardiomyocytes. Statistical analysis was performed using Student's $t$-test. The asterisks in the figure represent $P$-values below 0.05 


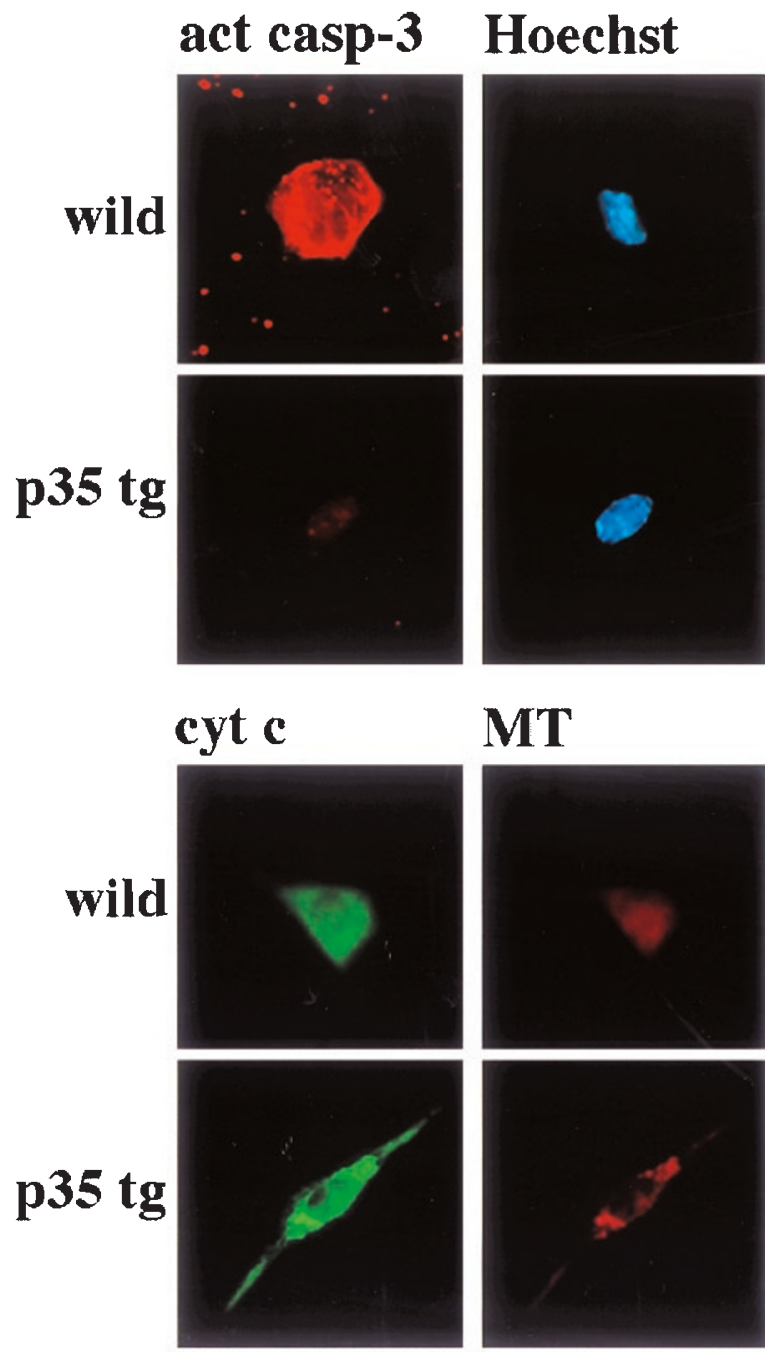

Figure 4 Immunostaining of the activated form of caspase- 3 and cytochrome c. A wild-type cardiomyocyte subjected to 48-h hypoxia exhibited immunoreactivity for the activated form of caspase-3, which was located diffusely in the cytoplasm. A p35-expressing cardiomyocyte exhibited no significant immunoreactivity for the activated form of caspase-3 after 48-h hypoxia. Cytochromec immunoreactivity showed a punctate pattern consistent with a mitochondrial localization as indicated by MitoTracker Red CMXRos, in a p35-expressing cell subjected to 48-h hypoxia. In a wild-type cardiomyocyte subjected to 48-h hypoxia, a diffuse pattern of cytochrome c immunoreactivity was observed. act casp-3: anti-activated caspase-3 staining. Hoechst: Hoechst 33342 staining. cytc: anti-cytochromec staining. MT: Mitotracker Red CMXRos staining. wild: cardiomyocytes from wild-type mice. p35 tg: cardiomyocytes from p35-transgenic mice

defective adenovirus encoding Cre recombinase under the control of the CAG promoter (AxCANCre). ${ }^{32}$ Infection efficiency was determined by $\beta$-galactosidase staining after infection with AxCALacZ at $2 \times 10^{5} \mathrm{pfu} / \mathrm{ml}$, and was observed to be $>90 \%$ at $48 \mathrm{~h}$ (data not shown). The number of cardiomyocytes was similar in wild-type and p35-transgenic mice before hypoxia $(85.9 \pm 28.4$ and $85.2 \pm 15.8$, wild-type and p35-transgenic mice, respectively). Under hypoxia, the number of remaining cardiomyocytes was significantly $(P<0.01)$ reduced to $34 \pm 7.9$ in wild-type mice. However, there was only a slight decrease in p35-transgenic mice $(68.8 \pm 16.0)$ (Figure $2 A)$. To determine whether the infected

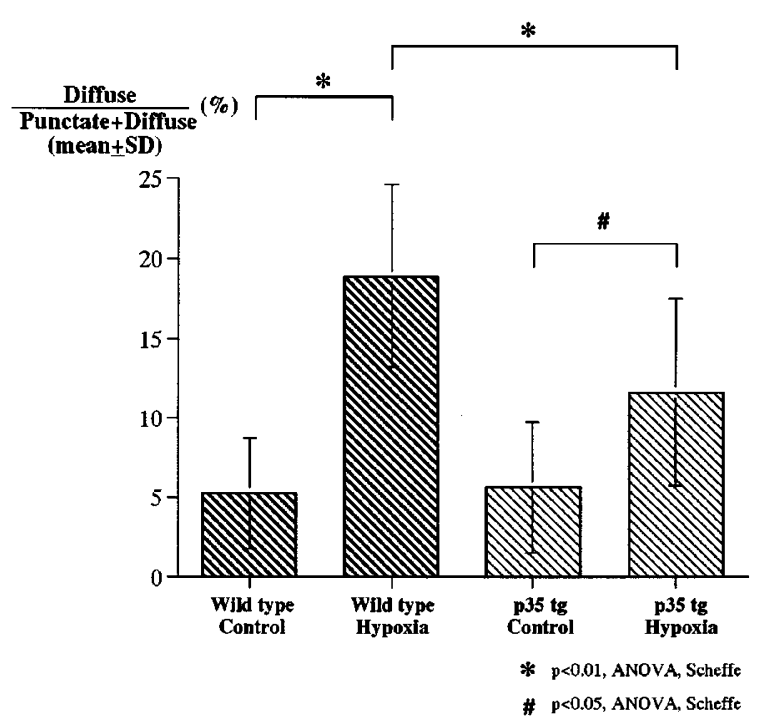

Figure 5 Cytochrome $c$ translocation in response to hypoxia. Cardiomyocytes from wild-type and p35-transgenic (p35tg) mice were infected with AxCANCre $\left(2 \times 10^{5} \mathrm{pfu} / \mathrm{ml}\right)$ for $24 \mathrm{~h}$, then placed under hypoxic conditions for $48 \mathrm{~h}$. The data were expressed as means \pm S.D. The results were obtained from 20 independent visual fields

Cre effectively mediated the switching on of $p 35$ expression in the cardiomycytes derived from transgenic mice, we performed RT-PCR, using the p35-4 and neo-2 primers (see Materials and Methods). Expression of p35 transgene could not be detected in cardiomyocytes under normal culture conditions. After infection with AxCANCre, a single 800-bp PCR product was detected (Figure 1A). These results show that the Cre-mediated induction of p35 expression was achieved in the cardiomyocytes. We then used TUNEL staining to examine the DNA fragmentation of cardiomyocytes attached to the dish $48 \mathrm{~h}$ after hypoxic stress. The proportions of cardiomyocytes showing DNA fragmentation after hypoxia were $19.7 \pm 3.2$ and $9.0 \pm 4.0 \%$ in wild-type and p35-transgenic mice, respectively (Figure 2B). These results indicate that $\mathrm{p} 35$ prevents the hypoxia-induced cell death of cardiomyocytes.

\section{Hypoxia-induced caspase activation was prevented by $\mathrm{p} 35$}

Cultured cardiomyocytes from neonatal mice exposed to hypoxic conditions showed higher caspase-3 like protease activity than normoxic time-matched controls (Figure $3 \mathrm{~A}$ ). This rise in caspase activity was more robust at $48 \mathrm{~h}$ hypoxia (3.8 times control) than $24 \mathrm{~h}$ (1.4 times control). The high caspase activity of cardiomyocytes under hypoxia was in proportion to cardiomyocyte viability. In contrast, caspase-1 like protease activity did not change as much as the caspase-3 like protease activity did (data not shown). To test the effect of p35 on changes in caspase activity, cardiomyocytes were infected with AxCANCre or AxCALacZ for $24 \mathrm{~h}$ before hypoxic stress, then cultured under hypoxic conditions for $48 \mathrm{~h}$. At $48 \mathrm{~h}$ of hypoxic stress, 40.5 units of caspase- 3 like protease activity were detected in the lysate from cells infected with AxCALacZ, while only 15.7 units of DEVDase activity were 
detected in the lysate from AxCANCre-infected cells (Figure 3B). Cardiomyocytes from wild-type mice, but not from p35transgenic mice, were positive for activated caspase-3 (Figure 4). These results suggest that p35 prevents the hypoxiainduced activation of caspase-3 in cardiomyocytes.

\section{p35 prevents cytochrome c release induced by hypoxic stress}

A number of reports have shown that the release of cytochrome $\mathrm{c}$ from mitochondria to the cytosol initiates caspase-3 activation through the aggregation of Apaf-1, procaspase-9, and dATP, and the subsequent activation of caspase-9, which in turn activates caspase- $3 .{ }^{35,36}$ In healthy cardiomyocytes, immunostaining for cytochrome $\mathrm{c}$ showed a punctate pattern that corresponded with the localization of mitochondria, as revealed by the mitochondrial marker MitoTracker Red (data not shown). Under hypoxic conditions, a diffuse pattern of cytochrome c staining was seen, indicating cytochrome $\mathrm{c}$ translocation into the cytoplasm (Figure 4). In p35-expressing cells, a punctate staining pattern for cytochrome $\mathrm{c}$ remained under hypoxic conditions (Figure 4). Under normal conditions, the proportion of cardiomyocytes displaying a diffuse staining pattern for cytochrome $\mathrm{c}$ was similar in both wild-type and p35transgenic mice $(5.3 \pm 3.5$ and $5.6 \pm 4.1 \%$ for wild-type and p35-transgenic mice, respectively). Under hypoxia, $18.9 \pm 5.7 \%$ of the remaining cardiomyocytes exhibited a diffuse pattern in wild-type mice, indicating an increased occurrence of cytochrome c translocation. In p35-transgenic mice, the proportion of cardiomyocytes showing a diffuse pattern was $11.6 \pm 5.9 \%$ (Figure 5 ). These results suggest that p35 can reduce hypoxic stress-induced cardiomyocyte injury upstream of cytochrome c release.

\section{Discussion}

We could successfully express $p 35$ in cardiomyocytes from p35 transgenic mice by infecting them with a recombinant adenovirus bearing the Cre recombinase, AxCANCre. Recombinant adenovirus vectors are widely used for the delivery of genes of interest into postmitotic cells such as neurons and cardiomyocytes. ${ }^{37-39}$ However, some foreign genes can not be produced using recombinant adenoviruses if the gene products result in growth discharge, toxicity, or have other adverse effects on the host cells. Since overexpression of $p 35$ results in growth suppression in mouse 3 T3 fibroblasts, ${ }^{40}$ we speculated that the production of a recombinant adenovirus carrying $p 35$ could be difficult. In such a case, a dual infection strategy using the Cre-loxP system could be applied to produce p35 using a recombinant adenovirus. The Cre-loxP system was used to deliver recombinant adenovirus-mediated exogenous $\mathrm{Bcl}-2$ into postmitotic neurons. ${ }^{41}$ The authors simultaneously infected neurons with two recombinant retroviruses; one was AxCANCre and the other was a loxP-bcl-2 adenovirus. Only neurons infected with both recombinant adenoviruses could express $b c /-2 .{ }^{41}$ However, there is a limitation to achieving high infection efficiency: the dual virus infection sometimes exhibits cytotoxicity. ${ }^{41}$ In contrast, the cells from our p35 transgenic mice require only a single infection with AxCANCre to activate the expression of $p 35$. Therefore, we can use a relatively low titer of recombinant adenovirus to achieve a high efficiency of infection and p35 expression. Expression of foreign genes are transient in case of adenovirus-mediated gene transfer. Since adenovirus can not be integrated into chromosome, replication defective recombinant adenovirus can be diluted through cell proliferation. Even in post-mitotic cells, difficulty of long term expression has been reported. ${ }^{42}$ Once stuffer sequence is removed from the genome of cells derived from loxP-p35 transgenic mice, expression of p35 is expected to continue as long as cell survives. This is another advantage of our strategy compared to dual infection method.

A number of Cre-transgenic mice or Cre-knock-in mice have been reported to express Cre under the regulation of a variety of tissue specific promoters e.g., the insulin promoter for pancreatic $\beta$-cells; the myosine light chain $2 v$ locus for cardiac ventricular muscle; and the $\mathrm{Ca}^{2+}$ / calmodulin-dependent protein kinase Ila-promoter for the pyramidal cells of the hippocampal CA1 region. ${ }^{43-45} \mathrm{By}$ crossing these mice with loxP-p35 mice, we can express p35 in many tissues of interest. Our p35 transgenic mice can provide a useful model for examining the involvement of caspases in development and/or in various models of degenerative diseases in vitro as well as in vivo.

The involvement of caspases in heart development has been examined. ${ }^{46}$ In cardiomyocytes, NO-mediated apoptosis is cGMP dependent and involves caspases. ${ }^{47}$ Caspase-3like protease is involved in staurosporine-induced apoptosis in cardiomyocytes. $^{48}$ Z-VAD-fmk was effective in reducing myocardial reperfusion injury, which could be at least partially attributed to the attenuation of cardiomyocyte apoptosis. ${ }^{30}$ However, all the results mentioned above were obtained using pharmaceutical caspase inhibitors. Since Z-VAD-fmk has been reported to inhibit calpain as well, ${ }^{31}$ we decided to use the pan-caspase inhibitor p35 to evaluate the involvement of caspases in hypoxia-induced cardiomyocyte injury. To our knowledge, our present data is the first demonstration that caspase-3-like protease activity is involved in hypoxiainduced cardiomyocyte cell death, and that inhibition of caspase-3-like protease activity by p35 can prevent cardiomyocyte death. We further showed that p35 prevents hypoxic stress-induced cardiomyocyte death upstream of cytochrome $c$ release. It has recently been reported that ZVAD-fmk fails to prevent cytochrome $c$ release in hypoxia- and ischemiainduced cardiomyocyte apoptosis. ${ }^{49,50}$ but ZDEVD-fmk prevents cytochrome $c$ release. ${ }^{50}$ These results further support our p35-expressing system as a useful experimental model to investigate the physiological roles of caspases in cell death.

\section{Materials and Methods}

\section{Transgenic mice}

A transgene consisting of the CAG promoter, loxP-neo-loxP, p35 coding sequence and a polyadenylation signal was microinjected into fertilized eggs of $\mathrm{C} 57 \mathrm{BL} / 6$ (B6) mice to generate transgenic mice as previously described. ${ }^{29}$ The presence of the p35 transgene was also detected by PCR. The primers used in the 
PCR were as follows: forward: 5'-TGGATGGATTCCACGATAGC-3' (p35-3); reverse: 5'-TGCACACTCTCCACGTAAGC-3' (p35-4). The DNA was denatured for $5 \mathrm{~min}$ at $94^{\circ} \mathrm{C}$ prior to $35 \mathrm{PCR}$ cycles at $94^{\circ} \mathrm{C}$ for $1 \mathrm{~min}, 55^{\circ} \mathrm{C}$ for $1 \mathrm{~min}$, and $72^{\circ} \mathrm{C}$ for $1 \mathrm{~min}$. The PCR products were fractionated by electrophoresis in $1.2 \%$ agarose gels and a band of approximately $500 \mathrm{bp}$ was identified in the presence of p35 the transgene. Expression of the transgene was detected by Reverse Transcription PCR (RT-PCR). Total RNA was prepared from the tissues of a transgenic mouse by using Trizol (Gibco $\mathrm{BRL})$. One $\mu \mathrm{g}$ of total RNA was incubated at $65^{\circ} \mathrm{C}$ for $10 \mathrm{~min}$, then cooled on ice for $5 \mathrm{~min}$. First-strand cDNAs were synthesized by mixing the RNA with $9 \mathrm{pM}$ random deoxynucleotide hexamers, $1 \times$ reverse transcription buffer (Gibco $B R L$ ), $6.7 \mathrm{mM}$ dithiothreitol (Gibco BRL), and $0.625 \mathrm{mM}$ deoxynucleotide triphosphates (Gibco $\mathrm{BRL}$ ) and incubating for $120 \mathrm{~min}$ at $37^{\circ} \mathrm{C}$ in the presence of 0.8 unit of RNase inhibitor (Promega) and 4 units of MoMLV reverse transcriptase (Promega). The primer sequences used for RT-PCR were as follows: forward 5'-TCTGACTGACCGCGTTACTCC-3 (neo2); reverse 5'-TATTCGGCAAGCAGGCATCG-3' (neo3). The following conditions were used for PCR reactions: $1 \times$ Ex Taq PCR buffer (TaKaRa), $0.2 \mathrm{mM}$ deoxynucleotide triphosphates (TaKaRa), $0.5 \mathrm{mM}$ each primer, and 1 unit of Ex Taq DNA polymerase (TaKaRa) in a total volume of $20 \mu \mathrm{l}$. The DNA was denatured for $5 \mathrm{~min}$ at $94^{\circ} \mathrm{C}$ prior to $35 \mathrm{PCR}$ cycles at $95^{\circ} \mathrm{C}$ for $1 \mathrm{~min}, 55^{\circ} \mathrm{C}$ for $1 \mathrm{~min}$, and $72^{\circ} \mathrm{C}$ for $1 \mathrm{~min}$.

\section{p35 expression by Cre-recombinase}

Cardiomyocytes from the p35 transgenic mice do not express p35 under normal conditions. Cre-recombinase excised the neomycin stuffer, allowing the p35 positioned behind the 2nd loxP site to express. To confirm p35 mRNA expression under Cre-recombinase expressing conditions, Reverse Transcription PCR (RT-PCR) was performed. Total RNA was prepared from p35 transgenic cardiomyocytes infected with the Cre-recombinase-expressing adenovirus (AxCANCre) using Trizol. Synthesis of the first-strand cDNAs was as above. The primer sequences used for RT-PCR were as follows: forward 5'-TCTGACTGACCGCGTTACTCC-3' (neo2); reverse 5'-TGCACACTCTCCACGTAAGC-3' (p35-4). The conditions for the PCR reactions were as described above.

\section{Cell culture}

The heart was removed from 1 to 3 -day-old C57/BL6 mice, rinsed with phosphate-buffered saline (PBS), minced with scissors, dispersed with $0.08 \%$ trypsin in PBS for $10 \mathrm{~min}$ at $37^{\circ} \mathrm{C}$, and pipetted approximately 30 times. The suspension was spun at 1300 r.p.m. for $3 \mathrm{~min}$ and the supernatant fraction was removed. Three additional incubations with the trypsin solution were performed, and the supernatant fractions from each digestion were combined with Dulbecco's modified Eagle's medium (DMEM)/Ham's F12 medium (Gibco BRL) supplemented with $10 \%$ fetal bovine serum (FBS) and $50 \mu \mathrm{g} / \mathrm{ml}$ ampicillin. The combined solution was spun at 1300 r.p.m. for $3 \mathrm{~min}$. The pellet was resuspended in DMEM/F12/ FBS, and the cells were plated onto a petri dish (CORNING) and incubated at $37^{\circ} \mathrm{C}$ for $60 \mathrm{~min}$ (to remove non-cardiomyocytes by differential adhesion). The non-attached cells were then seeded into $6 \mathrm{~cm}$ tissue culture dishes (CORNING), then incubated at $37^{\circ} \mathrm{C}$ for $48-72 \mathrm{~h}$ under a humidified atmosphere of $95 \%$ air, $5 \% \mathrm{CO}_{2}$. When the cells exhibited synchronous contractions, they were utilized for hypoxic stress.

\section{Hypoxic stress}

An anaerobic jar was used to expose the cells to hypoxic stress (Gas Pak system, BECTON DICKINSON). The medium for cardiomyocytes was replaced with DMEM/F12/5\%FBS before the cells were exposed to hypoxic stress. The cells were then placed in the anaerobic jar for 24 or $48 \mathrm{~h}$. Cardiomyocytes were infected with an aliquot of adenovirus carrying either the Cre-recombinase gene (AxCANCre) ${ }^{32}$ or the lacZ gene $(A x C A L a c Z)^{32}$ at a concentration of $2 \times 10^{5} \mathrm{pfu} / \mathrm{ml}$. After $24 \mathrm{~h}$, cells were subjected to oxygen deprivation in the anaerobic chamber.

\section{Immunocytochemistry}

Immediately after oxygen deprivation, the cells were washed three times with PBS (pH 7.4), and fixed in PBS containing $4 \%$ paraformaldehyde for $10 \mathrm{~min}$. Following three washes with PBS, the cells were permeabilized with $0.1 \%$ Triton-X/PBS for $10 \mathrm{~min}$. After three washes with PBS, the cells were incubated in $4 \%$ normal goat serum (NGS)/PBS at room temperature for $1 \mathrm{~h}$, then rabbit polyclonal anti-caspase-3 antibody (Pharmingen) at a dilution of $1: 200$ at $4{ }^{\circ} \mathrm{C}$ overnight. After washing with PBS three times, the cells were incubated with rhodamine-conjugated anti-rabbit IgG at a dilution of 1:200 at room temperature for $2 \mathrm{~h}$. Nuclear morphology was visualized by Hoechst 33342 $(10 \mu \mathrm{M})$ staining.

Cardiomyocytes harvested as described above were subjected to hypoxia for $48 \mathrm{~h}$. Cardiomyocytes grown under identical conditions except for hypoxia were used as controls. Prior to fixation, the cells were incubated in DMEM containing $200 \mathrm{nM}$ Mitotracker Red CMXRos (Molecular Probes) for $30 \mathrm{~min}$. Subsequently, the cells were fixed in $4 \%$ paraformaldehyde/PBS, permeabilized with $0.1 \%$ Triton X-100/PBS, and blocked with $4 \%$ normal goat serum/PBS. Mouse monoclonal anti-cytochrome $\mathrm{C}$ antibody (Pharmingen) at a dilution of $1: 200$ was applied at $4{ }^{\circ} \mathrm{C}$ overnight. After washing with PBS three times, the cells were incubated with FITC-conjugated anti-mouse $\lg$ at a dilution of $1: 200$ at room temperature for $2 \mathrm{~h}$. The cardiomyocytes were observed using a Carl-Zeiss Axiophoto 2 fluorescence microscope. To assess the translocation of cytochrome $c$ from mitochondria, the number of cardiomyocytes showing a diffuse staining pattern was determined from 20 independent random samplings of approximately 100 cells each and expressed as a percentage of the total cell number. The statistical analysis was performed using ANOVA followed by Scheffé's post hoc test.

\section{TUNEL method}

The TUNEL method was performed according to the manufacturer's instructions with these modifications (Apoptag, INTERGEN). After fixation, cells were incubated in Equilibration Buffer at room temperature for $3 \mathrm{~min}$. A working-strength terminal deoxynucleotidyl transferase mixture containing digoxigeninlabeled dUTP was applied in a humidified chamber at $37^{\circ} \mathrm{C}$ for $1 \mathrm{~h}$. The reaction was terminated using STOP/WASH Buffer. After three washes with PBS, the cells were incubated with FITC-conjugated anti-digoxigenin IgG at a dilution of $1: 200$ at $4^{\circ} \mathrm{C}$ overnight. Counterstaining with Hoechst 33342 was carried out as described above. To assess the proportion of cardiomyocytes exhibiting DNA fragmentation, TUNEL-positive cells were counted from six independent random samplings of approximately 150 cells each and expressed as a percentage of the total cell number. The statistical analysis was performed using a non-paired $t$-test. 


\section{Caspase activity}

Cultured cardiomyocytes were washed with PBS, then detached from the dish with trypsin-EDTA (Gibco BRL) at $37^{\circ} \mathrm{C}$ for $5 \mathrm{~min}$. An equal volume of DMEM/F12/5\% FBS was added to stop the trypsinization. Dissociated cells were collected by centrifugation at 1500 r.p.m. for $5 \mathrm{~min}$. The cell pellet was resuspended in $30 \mu \mathrm{l}$ of $50 \mathrm{mM}$ Tris- $\mathrm{HCl}, \mathrm{pH}$ 7.5, 1 mM EDTA, $10 \mathrm{mM}$ EGTA. Cells were disrupted by freezing and thawing (three cycles). Digitonin was added (15 $\mu \mathrm{M}$ final concentration) to the cell suspension followed by incubation at $37^{\circ} \mathrm{C}$ for $30 \mathrm{~min}$. Cell lysates were collected after centrifugation at 15000 r.p.m. for $3 \mathrm{~min}$. Lysates containing $3 \mu \mathrm{g}$ protein were preincubated with $10 \mu \mathrm{l}$ of cleavage buffer (20 mM HEPES-NaOH, pH 7.5, $100 \mathrm{mM} \mathrm{NaCl}, 0.05 \%$ $\mathrm{NP} 40,5 \mathrm{mM} \mathrm{MgCl}_{2}$ ) at $37^{\circ} \mathrm{C}$ for $60 \mathrm{~min}$, then $180 \mu$ l of cleavage buffer containing $10 \mu \mathrm{M}$ Ac-DEVD-7-amino-4-methylcoumarin (Peptide Institute, Osaka, Japan) was added and the mixtures were incubated at $37^{\circ} \mathrm{C}$ for $60 \mathrm{~min}$. The amount of 7-amino-4-methylcoumarin (AMC) released was measured using a spectrofluorometer (Biolumin 960, Molecular Dynamics) with excitation at $380 \mathrm{~nm}$ and emission at $460 \mathrm{~nm}$. One unit was defined as the amount of enzyme required to release $0.22 \mathrm{nmol} A M C$ per minute at $37^{\circ} \mathrm{C}$.

\section{Acknowledgements}

We are grateful to I Saito at University of Tokyo for providing us recombinant Adenovirus AxCANCre and AxCALacZ. This work was supported in part by grants from the Japanese Ministry of Education, Science, Sports and Culture to $\mathrm{H}$ Okano and M Miura, from Human Frontier Science Program to H Okano. This work was also supported in part to $\mathrm{H}$ Okano by Core Research for Evolutional Science and Technology (CREST), Japan Science and Technology Corporation. S Hisahara is a research fellow of the Japan Society for the Promotion of Science.

\section{References}

1. Smith KG, Strasser A and Vaux DL (1996) CrmA expression in T lymphocytes of transgenic mice inhibits CD95 (Fas/APO-1)-transduced apoptosis, but does not cause lymphadenopathy or autoimmune disease. EMBO J. 15: 5167-5176

2. Walsh CM, Wen BG, Chinnaiyan AM, O'Rourke K, Dixit VM and Hedrick SM (1998) A role for FADD in T cell activation and development. Immunity. 8: 439449

3. Tewari M and Dixit VMJ. (1995) Fas- and tumor necrosis factor-induced apoptosis is inhibited by the poxvirus crmA gene product. J. Biol. Chem. 270: 3255-3260

4. Miura M, Friedlander RM and Yuan J (1995) Tumor necrosis factor-induced apoptosis is mediated by a CrmA-sensitive cell death pathway. Proc. Natl. Acad. Sci. USA 92: 8318-8322

5. Gagliardini V, Fernandez PA, Lee RK, Drexler HC, Rotello RJ, Fishman MC and Yuan J (1994) Prevention of vertebrate neuronal death by the crmA gene. Science 263: 826-828

6. Wang L, Miura M, Bergeron L, Zhu H and Yuan J (1994) Ich-1, an Ice/ced-3related gene, encodes both positive and negative regulators of programmed cell death. Cell 78: 739-750

7. Sugimoto A, Friesen PD and Rothman JH (1994) Baculovirus p35 prevents developmentally programmed cell death and rescues a ced-9 mutant in the nematode Caenorhabditis elegans. EMBO J. 13: 2023-2028

8. Hay BA, Wolff T and Rubin GM (1994) Expression of baculovirus P35 prevents cell death in Drosophila. Development 120: 2121-2129

9. Sawamoto K, Taguchi A, Hirota Y, Yamada C, Jin MH and Okano H (1998) Argos induces programmed cell death in the developing Drosophila eye by inhibition of the Ras pathway. Cell Death Differ. 5: 262-270

10. Clem RJ, Fechheimer M and Miller LK (1991) Prevention of apoptosis by a baculovirus gene during infection of insect cells. Science, 254: 1388-1390
11. Rabizadeh S, LaCount DJ, Friesen PD and Bredesen DE (1993) Expression of the baculovirus p35 gene inhibits mammalian neural cell death. J Neurochem. 61: $2318-2321$

12. Clem RJ and Miller LK (1994) Control of programmed cell death by the baculovirus genes $\mathrm{p} 35$ and iap. Mol. Cell Biol. 14: 5212-5222

13. Hershberger PA, LaCount DJ and Friesen PD (1994) The apoptotic suppressor P35 is required early during baculovirus replication and is targeted to the cytosol of infected cells. J. Virol. 68: 3467-3477

14. Beidler TR, Tewari M, Friesen PD, Poirier G and Dixit VM (1995) The baculovirus p35 protein inhibits Fas- and tumor necrosis factor-induced apoptosis. J. Biol. Chem. 270: 16526-16528

15. Martinou I, Fernandez PA, Missotten M, White E, AlletB, Sadoul R and Martinou JC (1995) Viral proteins E1B19K and p35 protect sympathetic neurons from cell death induced by NGF deprivation. J. Cell Biol. 128: 201-208

16. Robertson NM, Zangrilli J, Fernandes-Alnemri T, Friesen PD, Litwack $G$ and Alnemri ES (1997) Baculovirus P35 inhibits the glucocorticoid-mediated pathway of cell death. Cancer Res. 57: 43-47

17. Hisahara S, Shoji S, Okana H and Miura M (1997) ICE/CED-3 family executes oligodendrocyte apoptosis by tumor necrosis factor. J. Neurochem. 69: 10-20

18. Bump NJ, Hackett M, Hugunin M, Seshagiri S, Brady K, Chen P, Ferenz C, Franklin S, Ghayur T, Li P, Licari P, Mankovich J, Shi L, Greenberg AH, Miller LK and Wong WW (1995) Inhibition of ICE family proteases by baculovirus antiapoptotic protein p35. Science 269: 1885-1888

19. Xue D and Horvitz HR (1995) Inhibition of the Caenorhabditis elegans cell-death protease CED-3 by a CED-3 cleavage site in baculovirus p35 protein. Nature 377: $248-251$

20. Ahmad M, Srinivasula SM, Wang L, Litwack G, Fernandes-Alnemri T and Alnemri ES (1997) Spodoptera frugiperda caspase-1, a novel insect death protease that cleaves the nuclear immunophilin FKBP46, is the target of the baculovirus antiapoptotic protein p35. J Biol Chem. 272: 1421-1424

21. Villa P, Kaufmann SH and Earnshaw WC (1997) Caspases and caspase inhibitors. Trends Biochem. Sci. 22: 388-393

22. Zhou Q, Krebs JF, Snipas SJ, Price A, Alnemri ES, Tomaselli KJ and Salvesen GS (1998) Interaction of the baculovirus anti-apoptotic protein p35 with caspases. Specificity, kinetics, and characterization of the caspase/p35 complex. Biochemistry 37: 10757-10765

23. Izquierdo M, Grandien A, Criado LM, Robles S, Leonardo E, Albar JP, de Buitrago GG and Martinez-A C (1999) Blocked negative selection of developing T cells in mice expressing the baculovirus p35 caspase inhibitor. EMBO J. 18: $156-166$

24. Kuida K, Zheng TS, Na S, Kuan C, Yang D, Karasuyama H, Rakic P and Flavell RA (1996) Decreased apoptosis in the brain and premature lethality in CPP32deficient mice. Nature 384: $368-372$

25. Woo M, Hakem R, Soengas MS, Duncan GS, Shahinian A, Kagi D, Hakem A, McCurrach M, Khoo W, Kaufmann SA, Senaldi G, Howard T, Lowe SW and Mak TW (1998) Essential contribution of caspase 3/CPP32 to apoptosis and its associated nuclear changes. Genes Dev. 12: 806-819

26. Kuida K, Haydar TF, Kuan CY, GuY, Taya C, KarasuyamaH, Su MS, Rakic P and Flavell RA (1998) Reduced apoptosis and cytochrome c-mediated caspase activation in mice lacking caspase 9. Cell 94: 325-337

27. Hakem R, Hakem A, Duncan GS, Henderson JT, Woo M, Soengas MS, Elia A, de la Pompa JL, Kagi D, Khoo W, Potter J, Yoshida R, Kaufman SA, Lowe SW, Penninger JM and Mak TW (1998) Differential requirement for caspase 9 in apoptotic pathways in vivo. Cell 94: 339-352

28. Varfolomeev EE, Schuchmann M, Luria V, Chiannilkulchai N, Beckmann JS, Mett IL, Rebrikov D, Brodianski VM, Kemper OC, Kollet O, Lapidot T, Soffer D, Sobe T, Avraham KB, Goncharov T, Holtman H, Lonai P and Wallach D (1998) Targeted disruption of the mouse Caspase 8 gene ablates cell death induction by the TNF receptors, Fas/Apo1, and DR3 and is lethal prenatally. Immunity 9:267276

29. Hisahara S, Araki A, Sugiyama F, Yagami K, Suzuki M, Abe K, Yamamura K, Miyazaki J, Momoi T, Saruta T, Bernard CCA, Okano H and Miura M (2000) Targeted expression of baculovirus p35 caspase inhibitor in oligodendrocytes protects mice against autoimmune-mediated demyelination, EMBO J 19: 341 348

30. Yaoita H, Ogawa K, Maehara Kand Maruyama Y (1998) Attenuation of ischemia/ reperfusion injury in rats by a caspase inhibitor. Circulation $97: 276-281$ 
31. Wolff BB, Goldstein JC, Stennicke HR, Beere H, Amarante-Mendes GP, Salvesen GS and Green DR (1999) Calpain functions in a caspase-independent manner to promote apoptosis-like events during platelet activation. Blood 94: 1683-1692

32. Kanegae Y, Lee G, Sato Y, Tanaka M, Nakai M, Sakaki T, Sugano S and Saito I (1995) Efficient gene activation in mammalian cells by using recombinant adenovirus expressing site-specific Cre recombinase. Nucleic Acids Res. 23 $3816-3821$

33. Niwa H, Yamamura K and Miyazaki J (1991) Efficient selection for highexpression transfectants with a novel eukaryotic vector. Gene. 108: 193-199

34. Lobe CG, Koop KE, Kreppner W, Lomeli H, Gertsenstein and Nagy A (1999) Z AP, a double reporter for cre-mediated recombination. Dev. Biol. 208: 281-292

35. Zou H, Henzel WJ, Liu X, Lutschg A and Wang X (1997) Apaf-1, a human protein homologous to $C$. elegans CED-4, participates in cytochrome c-dependent activation of caspase-3. Cell 90: $405-413$

36. Green DR and Reed JC (1998) Mitochondria and apoptosis. Science 281 $1309-1312$

37. Le Gal La Salle G, Robert JJ, Berrard S, Ridoux V, Stratford-Perricaudet LD, Perricaudet $M$ and Mallet $J$ (1993) An adenovirus vector for gene transfer into neurons and glia in the brain. Science 259: 988-990

38. Slack RS and Miller FD (1996) Viral vectors for modulating gene expression in neurons. Curr. Opin. Neurobiol. 6: 576-583

39. Long X, Crow MT, Sollott SJ, O'Neill L, Menees DS, de Lourdes Hipolito M, Boluyt MO, Asai T and Lakatta EG (1998) Enhanced expression of p53 and apoptosis induced by blockade of the vacuolar proton ATPase in cardiomyocytes. J. Clin Invest. 101: 1453-1461

40. Claveria C, Albar JP, Serrano A, Buesa JM, Barbero JL, Martinez-A C and Torres M (1998) Drosophila grim induces apoptosis in mammalian cells. EMBO J. 17: 7199-7208

41. Sato N, Wang S, Li L, Okabe K, Hashimoto M, Yaginuma H, Mikoshiba K, Uchiyama Y, Uetsuki T, Yoshikawa K, Milligan CE and Oppenheim RW (1998) A novel strategy for introducing exogenous bcl-2 into neuronal cells: the Cre/loxP system-mediated activation of bcl-2 for preventing programmed cell death using recombinant adenoviruses. Mol. Cell. Neurosci. 12: 65-78
42. Wang J, Ma Y and Knechtle SJ (1996) Adenovirus-mediated gene transfer into rat cardiac allografts. Comparison of direct injection and perfusion. Transplantation 61: 1726-1729

43. Kulkarni RN, Bruning JC, Winnay JN, Postic C, Magnuson MA and Kahn CR (1999) Tissue-specific knockout of the insulin receptor in pancreatic beta cells creates an insulin secretory defect similar to that in type 2 diabetes. Cell 96:329339

44. Hirota H, Chen J, Betz UA, Rajewsky K, Gu Y, Ross Jr J, Muller W and Chien KR (1999) Loss of a gp130 cardiac muscle cell survival pathway is a critical event in the onset of heart failure during biomechanical stress. Cell 97: 189-198

45. Tsien JZ, Chen DF, Gerber D, Tom C, Mercer EH, Anderson DJ, Mayford M, Kandel ER and Tonegawa S (1996) Subregion- and cell type-restricted gene knockout in mouse brain. Cell 87: 1317-1326

46. Watanabe M, Choudhry A, Berlan M, Singal A, Siwik E, Mohr S and Fisher SA (1998) Developmental remodeling and shortening of the cardiac outflow tract involves myocyte programmed cell death. Development 125: 3809-3820

47. Shimojo T, Hiroe M, Ishiyama S, Ito H, Nishikawa T and Marumo F (1999) Nitric oxide induces apoptotic death of cardiomyocytes via a cyclic-GMP-dependent pathway. Exp. Cell Res. 247: 38-47

48. Yue TL, Wang C, Romanic AM, Kikly K, KellerP, DeWolfJrWE, Hart TK, Thomas HC, Storer B, Gu JL, Wang X and Feuerstein GZJ (1998) Staurosporine-induced apoptosis in cardiomyocytes: A potential role of caspase-3. Mol Cell Cardiol 30: 495-507

49. Bialik S, Cryns VL, Drincic A, Miyata S, Wollowick AL, Srinivasan A and Kitsis N (1999) The mitochondrial apoptotic pathway is activated by serum and glucose deprivation in cardiac myocytes. Circulation Res. 85: 403-414

50. Malhorta R and Brosius III FC (1999) Clucose uptake and glycolysis reduce hypoxia-induced apoptosis in cultured neonatal rat cardiac myocytes. J. Biol. Chem. 274: 12567-12575 